\title{
Contingent Match Incentives Increase Donations
}

\section{Citation}

Anik, Lalin, Michael I. Norton, and Dan Ariely. "Contingent Match Incentives Increase Donations." JMR, Journal of Marketing Research (forthcoming).

\section{Permanent link}

http://nrs.harvard.edu/urn-3:HUL.InstRepos:12557293

\section{Terms of Use}

This article was downloaded from Harvard University's DASH repository, and is made available under the terms and conditions applicable to Open Access Policy Articles, as set forth at http:// nrs.harvard.edu/urn-3:HUL.InstRepos:dash.current.terms-of-use\#OAP

\section{Share Your Story}

The Harvard community has made this article openly available.

Please share how this access benefits you. Submit a story.

Accessibility 
Contingent Match Incentives Increase Donations

Lalin Anik, Duke University

Michael I. Norton, Harvard Business School

Dan Ariely, Duke University

Lalin Anik (corresponding author)

Post-Doctoral Fellow

Fuqua School of Business, Duke University

100 Fuqua Drive, Box 90120, Durham, North Carolina, USA 27708

lalin.anik@duke.edu

617.980.9607 


\section{Contingent Match Incentives Increase Donations}

We propose a new means by which non-profits can induce donors to give today and commit to giving in the future: contingent match incentives, in which matching is made contingent on the percentage of others who give (e.g., "if X\% of others give, we will match all donations”). A field experiment shows that a 75\% contingent match (where matches "kick in" only if 75\% of others donate) is most effective in increasing commitment to recurring donations. An online experiment reveals that the $75 \%$ contingent match drives commitment to recurring donations because it simultaneously provides social proof yet offers a low enough target that it remains plausible that the match will occur. A final online experiment demonstrates that the effectiveness of the $75 \%$ contingent match extends to one-time donations. We discuss the practical and theoretical implications of contingent matches for managers and academics.

Keywords: matching donations, social proof, prosocial behavior, charitable giving, plausibility 
Imagine making an online donation to a favorite charity; as you check out, you are given the option to upgrade to a recurring donation. If you are like many donors, you would be unlikely to make such a commitment. Now imagine that you see another message, informing you that the charity will match all donations made that day, if - and only if - $75 \%$ of donors agree to upgrade to a recurring donation. Would this type of matching incentive - what we term a contingent match - change your likelihood of upgrading? And if you were in this situation, what percentage would motivate you most? If the match were set to "kick in" if $25 \%$ of people upgraded, you might feel that while the match is likely to occur, the percentage being set so low indicates that very few people are expected to upgrade. In contrast, if the match were set at $100 \%$ of donors sending a strong signal that many people are expected to upgrade - you might feel that it is unlikely that fully $100 \%$ of people will agree, such that the likelihood of the match occurring is low. In a series of experiments, we examine the efficacy of contingent matches, exploring the ideal value for contingent matches to prove most effective.

What is that ideal value? One of our goals is to test different levels of contingent matches to find the most effective level - the level that provides sufficient social proof while remaining a plausible target. Previous research on social proof - where people are presented with the previous behavior of others in an effort to influence their own behavior - offers some evidence that targets around 70-75\% can be effective in motivating behavior. In field studies examining the impact of environmental appeals on hotel guests' towel reuse, appeals stating that $75 \%$ of guests reused their towels increased towel reuse (Goldstein, Cialdini and Griskevicius 2008). In a study exploring the influence of social proof on voting, Gerber and Rogers (2009) showed that stating that $71 \%$ of citizens voted in a previous election increased voter turnout. While we therefore suspected that $75 \%$ might prove an effective level for contingent matches, we note two 
crucial differences between previous research on social proof and our novel intervention of contingent matches. First, to our knowledge, the existing social proof research presents retrospective norms based on other respondents’ previous behavior; both Goldstein et al. (2008) and Gerber and Rogers (2009) informed respondents of the percentage of others who had already performed the desired behavior in the past. In contrast, we explore contingent matches in probabilistic scenarios where the behavior of others remains uncertain: our participants are not presented with information about actual past behavior, but rather are asked to consider a possible percentage of people who may perform a behavior in the future. Second, our use of contingent matches also means that we are not constrained by reality as are previous investigations of social proof. In order to state without deception that $75 \%$ of people have engaged in a given action, $75 \%$ of people actually have to have engaged in that action. In contrast, because contingent matches are probabilistic and relate to future behavior, we are free to vary the percentage ("if $25 \%$ engaged in the action," "if 50\% engage in the action," etc) without resorting to deception. These novel features of contingent matches, however, necessarily temper our ability to make definitive predictions about the ideal level of contingent matches, making our investigation somewhat exploratory.

\section{A Problem and Our Solution}

The 2011 Fundraising Effectiveness Survey Report notes that for every $\$ 5.35$ received in donations, \$5.54 was lost through donor attrition; indeed, donor attrition stands at 59\% in the past decade, compared to an average of just $5 \%$ attrition in for-profit enterprises. The same report notes that acquiring new donors is at least three times as expensive as retaining an existing donor. As a result, nonprofits are facing a major, costly problem. In a sector where financial 
uncertainty is high, recurring donations provide continuous and consistent revenue over the long term. A study conducted by Target Analytics in 2009 showed that one-time donors gave an average gift of $\$ 64$, while donors with recurring gifts gave an average of $\$ 23$. While the average monthly giving for recurring donors is lower on a per gift basis, however, the total revenue per donor each year is higher due to their increased frequency of giving. The increased returns from recurring donors are due not only to increased giving in year one but also to their higher retention rates across years. As a result, converting one-time donors to recurring donors allows nonprofits to receive more donations in a given year and increases their likelihood of retaining donors in the longer term.

How can nonprofits move donors from contributing one-time today to committing to recurring donations in the longer term? Despite the clear returns for recurring donations, the current donation models do not maximize their benefits. In most existing models for online donations, the donor browses the projects on the website, picks a cause, and is directed to the check-out page. The donor then determines the quantity and amount of donation, and makes a single donation. In our model, at the check-out page, the donor is incentivized to upgrade by contingent match incentives. Specifically, the donor is informed that his donation will be fully matched, but only if some percentage of donors also commit to future giving. We manipulate this percentage to document the percentage threshold that is most effective in inducing donors to upgrade to recurring donations. We also pit contingent matches (e.g., "if X\% of visitors also upgrade to recurring donations today, we will match your donation”) against standard matches (“we will match your donation”). Note that the likelihood of matching actually occurring is always higher with standard matches, where the match is certain. However, we explored 
whether, by offering social proof and suggesting plausible targets, contingent matches might be more effective than standard matches.

Why do we predict a critical mediating role for both social proof and plausibility in the effectiveness of contingent matches? Decades of research suggest that people’s behavior particularly in ambiguous situations - is shaped by the behavior of others (Asch 1956; Cialdini 1993; Griskevicius et al. 2006; Miller 1984; Sherif 1936). Social proof has been shown to guide a diverse set of actions such as helping in emergencies, littering, and recycling (Buunk and Bakker 1995; Cialdini, Reno, and Kallgren 1990; Latané and Darley 1968; Schultz 1999). Previous research suggests that consumers are sensitive to social proof when deciding to make one-time donations (e.g., Shearman and Yoo 2007); as a result, we expected that donors would also be sensitive to social proof when considering recurring donations. As described earlier, however, there is a critical difference between typical instantiations of social proof (" $\mathrm{X} \%$ of people have engaged in the behavior") and contingent matches ("If X\% of people engage in the behavior”); both suggest that many people have or are expected to engage in a behavior, but the latter has an element of uncertainty. As a result, we predicted an important role for another construct: plausibility. Certainly, individual motivation is strongly influenced by plausibility that goals can be reached (Bandura and Schunk 1981; Fishbach and Dhar 2005; Koo and Fishbach 2008; Zhang, Fishbach and Dhar 2007). We expected donors’ decisions to upgrade to recurring donations to therefore be influenced not only by social proof (where a higher percentage is generally better) but also by plausibility, where a percentage that is too high may seem unreachable. As noted above, we therefore explored the ideal value of contingent matches that would be most effective.

Overview of the Studies 
In one field and two online experiments, we assess the impact of contingent match incentives on donors' likelihood of committing to recurring monthly donations and making onetime donations. Study 1, conducted on the charity website GlobalGiving.org, varies the percentage of others who must commit to recurring donations in order for all donations to be matched, and compares the effectiveness of contingent matches to both a prompt to give and a standard match incentive. In Study 2, in addition to measuring likelihood of upgrading to recurring donations, we assess our proposed psychological mechanisms underlying the effectiveness of contingent match incentives: social proof and plausibility. Finally, Study 3 examines the effectiveness of contingent matches in encouraging one-shot donations.

\section{STUDY 1}

In Study 1, we explored the impact of contingent matching on donors' willingness to commit to monthly recurring donations. We partnered with Global Giving, a non-profit organization that connects donors with grassroots projects around the world. Potential donors can browse and select from a variety of projects that are organized by themes such as health care, the environment, and education. Upon choosing a project, a donor can contribute any amount using a credit/debit card, check, PayPal, or stock transfer.

Donors on the website were assigned to one of seven conditions: a control condition (the standard Global Giving website), a prompt condition in which they were encouraged to upgrade to a recurring donation, a standard match condition in which they were told their donations would be matched, or one of four contingent match conditions in which they were told that their donations would be matched only if [ $25 \%, 50 \%, 75 \%$, or $100 \%]$ of donors committed to recurring donations. As noted above, the standard match condition - which offers a certain match 
of funds - provides a conservative test of the power of contingent matching incentives, which by their nature are uncertain.

Method

The experiment was conducted on GlobalGiving.org between December 13, 2011 and January 23, 2012. During this period, there were 1,942 projects active on the website, which received 325,815 unique visitors.

Participants. In total, we collected data from 12,769 visitors (83\% from the US) to the GlobalGiving.org website. Global Giving did not collect age or gender, but provided us with the general demographics of their donors: 65\% female, with the majority between the ages of 18 to 55.

Procedure. After browsing the projects available, donors could click on a specific project of interest to learn more. On this project page, they were provided with several donation amounts in various increments (e.g., \$10, \$25, \$50) which varied from project to project, and an explanation for what each amount would fund (e.g., "\$10 sends a student to school”). See Appendix A, Panel 1, for a sample project page. Donors clicked on one of the set amounts on the project page; this amount was then carried forward to the checkout page.

The check-out page introduced donors to our experimental manipulations (see Appendix A, Panel 2 for the control condition; Appendix A, Panel 3 for the 75\% contingent match condition). Donors were randomly assigned to one of seven conditions on this checkout page. Donors in the control condition completed the standard check-out procedure. Those in the prompt condition read text that encouraged them to "help make a sustained impact by upgrading to a monthly recurring donation.” Those in the standard match condition read: “A generous anonymous donor has agreed to match $100 \%$ of new monthly donations today. Upgrade to a 
monthly recurring donation and get your donation matched!” Finally, donors in the four contingent match conditions read: “A generous anonymous donor has agreed to match $100 \%$ of new monthly donations today, but only if [25\%, 50\%, 75\%, or $100 \%]$ of donors start a recurring donation today. Upgrade to a monthly recurring donation and get your donation matched!”

Note that while the amount that donors clicked on the project page carried forward to this checkout page, donors were able to type in a different amount on the checkout page. As a result, base donation amounts were potentially influenced by our experimental manipulations; we used the number that donors typed into this box as our final base donation amount. On the same checkout screen on which they finalized their base donation amount, donors also decided whether or not to commit to recurring donations: a pull-down menu was set to "one-time” as the default, and donors could choose to change this frequency from "one-time" to "monthly recurring.” Our primary dependent measure was the percentage of donors who switched from a one-time to a monthly recurring donation. Note that recurring donations can be cancelled at any time.

\section{Results and Discussion}

A binary logistic regression analysis was conducted to predict recurring donation conversion rates. Our independent variable was the seven conditions and our binary dependent variable was whether donors upgraded to recurring donations $(0=n o, 1=y e s)$. A test of the full model against a constant only model was statistically significant, such that our conditions impacted donors' willingness to upgrade from one-time to monthly recurring donations, $\chi^{2}(6)=$ 14.87, $p=.02$. The Wald criterion demonstrated that only the $75 \%$ contingent match condition differed from the other conditions $(p=.01)$, as can be seen in Figure 1 , where the $75 \%$ contingent match condition generated higher conversion than all other conditions. Indeed, not 
only did donors in the $75 \%$ contingent match condition upgrade significantly more than those in the control condition ( $M=4.73 \%$ vs. 3.31\%), $t(3761)=2.23, p=.03$, the percentage of upgrades in the $75 \%$ contingent match condition was higher than in the standard match condition $(M=$ $3.08 \%), t(3578)=2.54, p=.01-$ despite the fact that this condition guaranteed that donations would be matched. In fact, upgrade rates were significantly higher in the 75\% contingent match than in all other conditions, $\chi^{2} s>4.96$, ps $<.03$, except for the $100 \%$ contingent match condition $(M=3.77 \%)$ where the difference was only marginal, $\chi^{2}(1)=2.16, p=.14$. However, upgrade rates in the $100 \%$ contingent match condition were not significantly higher than those in the control condition, $\chi^{2}(1)=.59, p=.44$. Indeed, none of the six conditions other than the $75 \%$ contingent match condition differed from each other, $\chi^{2} s<2.74$, all $p s>.10$, again suggesting the unique effect of this condition.

Finally, merely prompting donors (prompt condition) to upgrade to a monthly recurring donation did not by itself motivate commitment to recurring donations. If anything, the percent of one-time donations converted to monthly recurring donations in the prompt condition $(M=$ 2.84\%) was lower than in the control condition, though this difference was not significant, $t(3730)=.82, p=.41$

\section{[Insert Figure 1 about here]}

While our experimental manipulations were specifically - and successfully - targeted at increasing donors' likelihood of upgrading, understanding the total financial impact of our interventions requires an analysis of the dollar amounts donated. Therefore, we analyzed whether base amounts (the amount donors entered on the check-out page) varied by condition, for both one-time donors and donors who upgraded to recurring donations. For base amounts for one-time donors, the one-way ANOVA was significant, $F(6,12330)=2.68, p<.02$ (see Table 1 for 
means). The base amount was highest in the control condition followed by the $75 \%$ contingent match and 50\% contingent match; amounts across all conditions ranged from \$34.78 to \$37.83. For base amounts for recurring donors, the one-way ANOVA was significant, $F(6,425)=2.78, p$ $<.02$ (Table 1). The base amount was highest in the 25\% contingent match condition, followed by the $75 \%$ contingent match and 50\% contingent match (ranging between $\$ 28.04$ and \$36.27); base amounts were lower in the remaining four conditions (ranging from \$19.87 to \$24.27).

While donation amounts for the 75\% contingent match condition were in general among the highest for both one-time and recurring donors, no clear picture emerges for the particular effectiveness of any condition in increasing donations - not surprising given that our intervention was targeted at the decision to upgrade. It is clear, however, that donors who gave once $(M=$ $\$ 36.82, S D=27.95)$ gave significantly higher amounts than those who upgraded to recurring donations $(M=\$ 26.65, S D=24.26), t(12767)=7.47, p<.001$. It thus appears that donors who committed to recurring donations might have strategized by initially giving less. In order to understand the net effect of such behavior, we next examined donor retention. Approximately 23 months after the experiment, we gathered retention rates for each of our seven conditions, allowing us to calculate the impact of our interventions on total donations. ${ }^{1}$

Overall, donors made payments for more than one year $\left(M_{\text {months }}=13.90, S D=8.29\right)$. The one-way ANOVA across all conditions was not significant, $F(6,412)=1.38, p=.22$, and indeed Table 1 shows that the average retention for all conditions was roughly one year (ranging from 15.72 months in the control condition to 11.76 months in the standard match condition). As with amount of recurring donations, the 50\% contingent match and 75\% contingent match again produced the second and third highest values. Thus although recurring donors gave a smaller

\footnotetext{
${ }^{1}$ Due to a technical error involving donor identification numbers, we are unable to match the donor retention data with the original data set.
} 
base amount (\$26.65) than one-time donors (\$36.82), their average retention of more than one year $\left(M_{\text {months }}=13.90\right)$ meant that they gave an average of $\$ 370.44$. These results confirm that the conversion from one-time to recurring donations was indeed an upgrade.

Finally, all of the above metrics taken together allow us to calculate the overall effectiveness of our seven different conditions on total donations per donor (Table 1). Because recurring donors contributed far more than one-time donors, and because upgrade rates to recurring donations were significantly higher in the 75\% contingent match than all other conditions, the $75 \%$ contingent match condition had the highest average donations per donor (\$55.78). Indeed, this figure was more than \$5 higher than the next nearest condition, 25\% contingent match (\$50.66), and more than \$10 higher than the condition where matching was guaranteed, the standard match (\$42.27). Note that the effectiveness of all of our conditions depends on both the retention rate of donors who commit to recurring donations and the cost and probability of re-acquisition for one-time donors. Inherent in the positive impact of the $75 \%$ contingent match condition on increasing recurring donations is the reduction of the reacquisition costs necessary to induce one-time donors to donate again in the future.

\section{[Insert Table 1 about here]}

\section{STUDY 2}

Study 1 provides evidence for the effectiveness of contingent match incentives in inducing donors to upgrade to recurring donations - particularly when $75 \%$ of donors must comply for contingent matches to "kick in.” Because Study 1 was a field experiment, however, we were unable to directly assess the role of our proposed mediators, social proof and plausibility. In Study 2, we conducted a controlled online experiment in which we asked participants to engage in hypothetical donation decisions and complete a series of items 
assessing their perceptions of social proof and plausibility. In addition, we included measures of two other constructs that have been shown to influence donation behavior. First, the feeling of making progress towards a goal has been shown to influence people’s decision to give; second, the feeling that one is having prosocial impact - making a difference in the lives of specific others - can be a driver of giving (Cryder, Loewenstein and Seltman 2013; Grant 2007). While these constructs play a mediating role in many charitable contexts, we expected they would play less of a role in our context. First, our contingent matches do not give donors a sense of progress because no information is provided about how close the contingent match is to "kicking in." Second, research shows that feelings of prosocial impact are highest when giving to specific individuals and causes rather than to general causes (Aknin, Dunn, Whillans, Grant, \& Norton, 2013); in our context, donors who make the decision to upgrade to recurring donations commit to give to Global Giving each month, rather than to a specific beneficiary.

Because the prompt and standard match conditions did not increase recurring donations in Study 1, in Study 2 participants were assigned to one of five conditions: a control condition or one of four contingent match conditions: $25 \%, 50 \%, 75 \%$, or $100 \%$ ). We explored whether the 75\% contingent match incentive would again prove particularly effective in increasing recurring donations. We predicted that the effectiveness of contingent matches would be driven by them offering sufficient social proof (“many people are upgrading”) while remaining a plausible target (“it’s likely that the match will kick in”).

Finally, respondents in Study 1 were a self-selected sample who had decided to visit an online charitable giving website. In Study 2, we switched to an online sample from Amazon's Mechanical Turk; while still not perfectly representative, such samples have been used effectively in previous research (Buhrmester, Kwang, and Gosling 2011). For our purposes, this 
sample allows us to test the effectiveness of contingent matches on donations using a different set of participants who had not selected into a charitable giving website.

Method

Participants. Participants $\left(N=275,64 \%\right.$ male; $\left.M_{\text {age }}=29.6, S D=9.3\right)$ were recruited via Amazon’s Mechanical Turk services for an experiment about decisions in return for monetary compensation.

Procedure. Participants were asked to imagine they came across a project to help seriously ill children on the Global Giving website and that they were interested in supporting this cause. Participants were randomly assigned to one of five conditions, modified from the text used in Study 1. On the same page as the project information, those in each of the four contingent match conditions were informed that an anonymous donor had agreed to provide matching funds for people who donated. They read: "If [25\%, 50\%, 75\%, or 100\%] of people seeing this offer agree to upgrade to a monthly recurring donation today, we will match $100 \%$ of your donation. For example, if you give \$10 per month, we will donate an additional \$10.” Participants in the control condition were not provided with this information (see Appendix B for the information provided about the charitable cause, and the wording for the $75 \%$ contingent match condition).

On the next page, all participants were asked whether they would donate to this project (no/yes), and if yes, how much they would donate (open ended response). Participants were also asked whether they were willing to upgrade to a monthly recurring donation (no/yes) - our primary dependent measure.

To assess social proof, participants were asked: "What percent of people who see this message do you think would upgrade to a monthly recurring donation?” To measure plausibility, 
participants rated the likelihood that the project would reach its goal $(1=$ very unlikely to $7=$ very likely). Last, participants completed items assessing progress, "How much progress would your potential donation make toward the project's goal to help children?” and perceived impact, “How big would your contribution be toward the project's goal if you made a donation?”, on 7point scales $(1=$ not at all to $7=$ extremely $)$.

Results and Discussion

As in Study 1, we did not have specific predictions for the base amount donated, since our manipulations were targeted at changing participants' likelihood of upgrading. A one-way ANOVA did not approach significance, $F(4,270)=.06, p=.99$; base donation amounts ranged from $\$ 17.16$ to $\$ 18.51$, and did not differ between any of the conditions (all $p s>.72$ ).

We conducted a logistic regression analysis to predict recurring donation conversion rates. Our independent variable was the information provided across five conditions and our binary dependent variable was whether participants upgraded to recurring donations $(0=n o, 1=$ yes). As in Study 1, our conditions impacted participants' willingness to upgrade from one-time to monthly recurring donations, $\chi^{2}(4)=17.44, p=.002$. We replicated our results from the field study: conversion to monthly recurring donations peaked in the $75 \%$ contingent match condition $(M=58.2 \%)$, which was significantly different from the control condition $(M=30.9 \%), \chi^{2}(1)=$ 8.39, $p=.004$. Again replicating Study 1 , upgrade rates were significantly higher in the $75 \%$ contingent match than in all other conditions, $\chi^{2} s>8.28$, ps $<.01$, except for the $100 \%$ contingent match condition $(M=45.45 \%)$ where the difference was only directional, $\chi^{2}(1)=$ $1.79, p=.18$.

[Insert Figure 2 about here] 
As in Study 1, upgrade rates for the 75\% contingent match condition were highest, followed by those in the $100 \%$ contingent match. What accounts for this pattern? Our account suggests that while both the $75 \%$ and $100 \%$ contingent match conditions offer social proof leading to increased upgrades - the $75 \%$ contingent match will be higher in perceived plausibility of "kicking in" than the $100 \%$ contingent match, making the former relatively more effective than the latter.

Participants' perceptions of social proof - the percent of other people they believed would also convert to recurring donations - differed as a function of condition, $F(4,270)=$ 10.81, $p<.001$. As can be seen in Table 2 (which reports both means and significance levels), social proof in both the $75 \%$ contingent match and $100 \%$ contingent match was significantly higher than in each of the other three conditions; the $75 \%$ contingent match and $100 \%$ contingent match did not differ. Participants' ratings of the plausibility of the recurring donation goal being reached also varied by condition, $F(4,270)=8.63 .81, p<.001$. Importantly, however, the pattern of results differed from the pattern for social proof. As Table 2 shows, ratings of plausibility in the control, 25\% contingent match, 50\% contingent match, and 75\% contingent match did not differ from each other, but were all significantly higher than in the $100 \%$ contingent match condition. Taken together, these results suggest that the $75 \%$ contingent match condition hits a "sweet spot" where both social proof and plausibility are high.

We next examined ratings of progress and perceived impact; for each, we observed a significant effect of condition, $F(4,269)=3.32, p=.01$, and $F(4,270)=4.18, p=.003$, respectively. Interestingly, and as can be seen again in Table 2, both progress and perceived impact peaked in the $75 \%$ contingent match condition, followed by the $100 \%$ contingent match condition. 
[Insert Table 2 about here]

Mediation. Given that all four constructs appeared to show a particular inflection in the 75\% contingent match condition, we conducted a mediational model to assess which constructs served as significant mediators of the effectiveness of contingent match incentives. In these analyses, we include only the four contingent match incentive conditions (which are continuous) and omit the control condition since this condition does not include contingent incentives and is therefore categorically different.

Correlational analyses revealed that the four mediators were correlated with one another, all $r s>.27$, all $p s<.001$. We followed the hierarchical regression procedures recommended by MacKinnon, Fairchild, and Fritz (2007). First, when these four variables were entered into the mediation model, the impact of the conditions (four group conditions) on participants' willingness to upgrade to recurring donations was significantly reduced (from $b=.38, S E=.13$, $p=.003$, to $b=.24, S E=0.21, p=.25$ ), as can be seen in Figure 3. The $95 \%$ bias-corrected confidence intervals both for the indirect effects of social proof and for plausibility excluded zero ([.453, .477]) and ([-.117, -.122]), respectively, indicating two significant indirect effects. In contrast, neither progress $(b=.14, S E=0.26, p=.59)$ nor perceived impact $(b=.09, S E=0.26$, $p=.73$ ) predicted the dependent variable in our model. The $95 \%$ bias-corrected confidence intervals for the indirect effects of progress and perceived impact included zero ([-.093, .230]) and ([-.181, .218]), respectively, confirming their nonsignificant effects on recurring donations. Interestingly, the coefficients on progress and perceived impact are higher than the coefficient for social proof ( $b s=.14, .09$, and .06$)$ suggesting that these two mediators may have greater impact on average; however, the larger standard errors for these two variables compared to social proof (SEs $=.26 . .26$, and .01 ) suggest greater heterogeneity in their impact. In summary, these 
analyses suggest that the effect of contingent match incentives on conversion to recurring donations is mediated in particular by social proof and plausibility.

\section{[Insert Figure 3 about here]}

As can be seen comparing Figures 1 and 2, the percentage of participants who reported being willing to upgrade in Study 2 was far higher (range: $29.09 \%$ to 58.18\%) than the percentage who actually upgraded in Study 1 (range: $2.79 \%$ to $4.73 \%$ ), consistent with previous research suggesting that people overestimate their likelihood of engaging in prosocial behavior (Epley \& Dunning, 2000). Note that the effectiveness of the $75 \%$ contingent match occurs independent of the actual likelihood of the goal being reached: if participants were aware of population base rates of compliance, then a much lower contingent match (say, 5\%) might have been most effective in increasing compliance in Study 1 (since actual compliance ranged from 2.79\% to $4.73 \%$ ), whereas a higher percentage (say, 60\%) should have most effective in Study 2, where actual compliance ranged from $29.09 \%$ to $58.18 \%$. Indeed, in both studies, the percentage of compliance even in the most effective $75 \%$ contingent match condition was well below $75 \%$. Future research is needed to explore how awareness of population base rates might interact with ideal levels of contingent matches. In cases in which consumers are aware of the actual percentage of people engaging in some behavior than our participants appear to be in the domain of charitable giving, contingent match incentives may prove most effective when more closely linked to actual percentages.

\section{STUDY 3}

Studies 1 and 2 document the effectiveness of 75\% contingent match incentives on donors' willingness to upgrade to recurring donations. In Study 3, we examine whether the impact of contingent matches is specific to recurring donations, or extends to a simpler decision: 
one-time donations. In an online experiment, participants were randomly assigned to one of four conditions - standard match, 50\% contingent match, 75\% contingent match, or a control condition - and chose whether to keep a \$.50 payment or donate it to a charitable cause.

Method

Participants. Participants $\left(N=219,63 \%\right.$ male; $\left.M_{\text {age }}=31.3, S D=10.0\right)$ were recruited via Amazon’s Mechanical Turk service for an experiment about decisions in return for monetary compensation.

Procedure. Participants first completed an unrelated task in exchange for \$1.00. They were then presented with the same Global Giving project used in Study 2 - helping seriously ill children - and randomly assigned to one of four conditions. Those in the standard match condition were told that an anonymous donor had agreed to provide matching funds for people who donated. Those in one of the two contingent match conditions were told: "We will match your donation today, but only if [50\% or $75 \%$ ] of people seeing this offer agree to donate today." Those in the control condition were not provided with additional information. Next, all participants were given an opportunity to contribute $\$ .50$ of their earnings, and were asked whether they would like to donate the $\$ .50$ or keep it. Our primary dependent measure was the percent of people who decided to donate.

\section{Results and Discussion}

We conducted a logistic regression with our four conditions as the independent variable and whether participants donated $(0=$ no, $1=$ yes $)$ as the dependent variable. The analysis revealed a marginally significant effect across conditions on participants' willingness to donate, $\chi^{2}(3)=6.68, p=.08$. Most importantly, however, we replicated our results from Studies 1 and 2: participants' willingness to donate again peaked in the 75\% contingent match condition (49.1\%), 
which was significantly different from the control condition (26.5\%), $\chi^{2}(1)=5.66, p=.02$. Meanwhile, donation percentages in the standard match (33.3\%) and 50\% contingent match (31.0\%) conditions were not significantly different from the control condition or from each other, $\chi^{2} s<.58, p s>.45$.

\section{GENERAL DISCUSSION}

Results from a field experiment on GlobalGiving.org in which donors upgraded to recurring donations, an online experiment in which participants reported their intention to commit to recurring donations, and an online experiment in which participants engaged in onetime giving, converged to demonstrate the effectiveness of contingent matches. Informing potential donors that their donations would be matched if and only if $75 \%$ of other donors agreed to upgrade (Studies 1 and 2) or donate (Study 3) led to the highest compliance. Study 2 traces the effectiveness of the $75 \%$ contingent match to the fact that this inducement is high in both social proof and plausibility when compared with contingent matches at other percentages ( $25 \%, 50 \%$, and $100 \%)$.

Perhaps most strikingly, the $75 \%$ contingent match - an incentive that is not certain to "kick in" - proved to be more effective in inducing donors to upgrade than a standard match in which donations were guaranteed to be matched. Future research is needed to explore why standard matches perform relatively poorly compared to contingent match incentives. Indeed, previous research has offered mixed support for the effectiveness of matching donations (Benabou and Tirole 2006; Frey 1997; Gneezy 2003; Meier 2007). It is possible, for example, that one-to-one matching signals a well-funded organization that is therefore less need of support. If so, standard matches might diminish donors' feeling of making a difference, a critical driver of giving (Cryder et al. 2013; Grant 2007). 
In the introduction, we noted a critical and potentially useful difference between social proof paradigms and our contingent match paradigm: whereas social proof information is based on the previous behavior of others (“75\% of people have already voted”), contingent match incentives merely imply that many people are likely to engage in the behavior ("we expect that $75 \%$ of people donating is a plausible target - or we would not have set the match at this level.”) Despite the fact that contingent matches do not provide evidence of actual behavior, results from Study 2 clearly indicate that participants inferred social proof from the signal sent by contingent matches. One problem facing researchers and policymakers who seek to change people’s behavior by invoking normative data is that such data often does not point in the right direction, as when policymakers wish to encourage people to vote but must admit that only $25 \%$ of people voted in some previous election. Contingent match incentives - which instead send a signal of how many people are expected to engage in some behavior - are not bound by previous actual behavior; as a result, they may be particularly useful to invoke in situations where the frequency of the desired behavior is currently low.

While a large body of previous research has explored the impact of one of our mediators - social proof - on behavior (see Cialdini \& Goldstein, 2004 for a review), we introduce a construct that serves as a limiting factor on the effect of information about the behavior of others: plausibility. Specifically, we show that a 100\% contingent match - where an incentive will kick in only if fully $100 \%$ of consumers engage in a given behavior - leads consumers to feel that the target is unreachable, decreasing compliance. An interesting area for future research is to explore whether plausibility plays a similar limiting role in prototypical social proof paradigms. Imagine a case in which a marketer claimed that fully $100 \%$ of consumers had engaged in some action; would consumers similarly begin to doubt the likelihood of this claim? Indeed, it is possible that 
one reason that $70-75 \%$ seems to be an effective norm in previous research (Gerber \& Rogers 2009; Goldstein et al. 2008) is because, like the 75\% contingent match in our research, it provides sufficient social proof while remaining plausible. Relatedly, it would be fruitful for future research to explore a role for diffusion of responsibility in attenuating compliance. It is possible that when percentage of people expected to engage in some behavior becomes very high (as in the $100 \%$ contingent match condition) individual donors feel less personal responsibility to act themselves. Diffusion of responsibility is particularly interesting in the context of contingent match incentives since these incentives involve expectations of how others will behave - as in the classic bystander studies - and not their actual behavior.

This discussion also raises the notion that contingent match incentives might be used more broadly, beyond the context of charitable donations. In fact, if anything the current instantiation of contingent incentives may provide a relatively conservative test: donors do not have any information about the behavior of other donors, and donors are fully anonymous to each other. Imagine instead an office manager who wants each employee in her office to get a flu shot. Applying contingent incentives, this office manager could inform employees that each employee who receives a flu shot will receive a \$5 gift card to Starbucks - but that the incentive will double to a \$10 gift card if 50\% of employees receive flu shots, and quadruple to a \$20 gift card if 100\% comply. In such settings, not only could the office manager provide progress reports ("we are currently at $49 \%$ of employees and need just a few more for the $50 \%$ incentive to kick in”), but the compliance of employees could be made public, such that those employees who had already received flu shots could attempt to convince those who had not to comply. This additional public pressure might serve to enhance the effectiveness of contingent matches. In this case, we would again expect social proof and plausibility to play a crucial mediating role, and 
might also expect perceived progress to contribute to the effectiveness of contingent matches (Cryder et al. 2013).

Future research should also explore how contingent incentives can be used in for-profit contexts such as subscription services (e.g., magazines) and loyalty programs (e.g., airlines, hotels). Imagine an online newspaper aiming to increase loyalty that offers contingent rewards: "If $75 \%$ of people seeing this message sign up for annual subscriptions today, we will offer the first three months free.” Alternatively, for-profits could offer contingent rewards via online social networks such as Facebook and LinkedIn to encourage customers to reach out to their own networks: "If 75\% of your Facebook friends purchase this app today, we will offer all of you a free additional app.” It is of interest to explore whether the social aspect of contingent matches which we have shown are effective in prosocial domains - functions in the same manner in forprofit settings, and whether social proof and plausibility continue to play the crucial driving roles.

\section{Conclusion}

Non-profits that fail to convert one-time donors into recurring donors lose not only certain recurring revenue, but incur the inevitable costs of constant recruitment of new donors. We suggest, and provide evidence in Studies 1 and 2, that contingent match incentives are an effective and underutilized means of inducing people to become recurring donors. Indeed, as of November 2013, GlobalGiving.org continues to use the 75\% contingency match when offering matching campaigns, as they continue to report that recurring donation conversion rates are higher than baseline. While the company did not release full financials for the increase in donations they experienced when implementing contingent matches, Chief Product Officer Kevin Conroy noted that the contingent matches allowed Global Giving to double the amount of 
money they raise through recurring donations. Moreover, we also show that contingent matches are effective in encouraging shorter-term, one-time donations. Particularly given that there is little to no cost of implementing contingent matches - in this context, they involve merely adding text to a standard pitch - the return on investment is clearly high. 


\section{REFERENCES}

Aknin, Lara B., Elizabeth W. Dunn, Ashley V. Whillans, Adam M. Grant, and Michael I. Norton (2013), “Making a difference matters: Impact unlocks the emotional benefits of prosocial spending,” Journal of Economic Behavior and Organization, 88 (April), 90-95.

Association of Fundraising Professionals (2011), “2011 FEP Donor Retention Supplement,” (accessed 15 May 2013), [available at http://www.afpnet.org/files/ContentDocuments/FEP2011ReportSupplement-11-1811.pdf].

Asch, Solomon E. (1956), "Studies of independence and conformity: I. A minority of one against a unanimous majority,” Psychological Monographs: General and Applied, 70 (September), 1-70.

Bandura, Albert, and Dale H. Schunk (1981), “Cultivating competence, self-efficacy, and intrinsic interest through proximal self-motivation,” Journal of Personality and Social Psychology, 41 (March), 586-598.

Benabou, Roland, and Jean Tirole (2006), "Belief in a just world and redistributive politics,” The Quarterly Journal of Economics, 121 (February), 699-746.

Buhrmester, Michael, Tracy Kwang, and Samuel D. Gosling (2011), “Amazon’s Mechanical Turk: A new source of inexpensive, yet high-quality, data?,” Perspectives on Psychological Science, 6, 3-5.

Buunk, Bram P., and Arnold B. Bakker (1995), "Extradyadic sex: The role of descriptive and injunctive norms," Journal of Sex Research, 32 (July), 313-318.

Cialdini, Robert B. (1993), Influence (rev): The Psychology of Persuasion, HarperCollins. 
and Noah J. Goldstein (2004), “Social influence: Compliance and conformity,” Annual Review of Psychology, 55, 591-621.

, Raymond R. Reno and Carl A. Kallgren (1990), “A focus theory of normative conduct: Recycling the concept of norms to reduce littering in public places,” Journal of Personality and Social Psychology, 58 (June), 1015-1026.

Cryder, Cynthia E., George Loewenstein, and Howard Seltman (2013), “Goal gradient in helping behavior,” Journal of Experimental Social Psychology, 49 (November), 1078-1083.

Epley, Nicholas, and David Dunning (2000), “Feeling ‘holier than thou’: are self-serving assessments produced by errors in self-or social prediction?,” Journal of Personality and Social Psychology, 79 (December), 861-875.

Fishbach, Ayelet, and Ravi Dhar (2005), “Goals as excuses or guides: The liberating effect of perceived goal progress on choice,” Journal of Consumer Research, 32 (December), 370377.

Frey, Bruno S. (1997), Not Just for The Money. An Economic Theory of Personal Motivation, Cheltenham, UK: Edward Elgar.

Gerber, Alan S., and Todd Rogers (2009), "Descriptive social norms and motivation to vote: Everybody’s voting and so should you,” The Journal of Politics, 71 (January), 178-191.

Gneezy, Uri (2003), “The W Effect of Incentives,” Mimeo, University of Chicago Graduate School of Business.

Goldstein, Noah J., Robert B. Cialdini, and Vladas Griskevicius (2008), “A room with a viewpoint: Using social norms to motivate environmental conservation in hotels,” Journal of Consumer Research, 35 (October), 472-482. 
Grant, Adam M. (2007), “Relational job design and the motivation to make a prosocial difference,” Academy of Management Review, 32 (April), 393-417.

Griskevicius, Vladas, Noah J. Goldstein, Chad R. Mortensen, Robert B. Cialdini, and Douglas T. Kenrick (2006), “Going along versus going alone: when fundamental motives facilitate strategic (non) conformity,” Journal of Personality and Social Psychology, 91 (August), 281-294.

Koo, Minjung and Ayelet Fishbach (2008), “Dynamics of Self-Regulation: How (Un)accomplished Goal Actions Affect Motivation,” Journal of Personality and Social Psychology, 94 (February), 183-95.

Latané, Bibb, and John M. Darley (1968), “Group inhibition of bystander intervention in emergencies,” Journal of Personality and Social Psychology, 10 (November), 215-221.

MacKinnon, David P., Amanda J. Fairchild, and Matthew S. Fritz (2007), “Mediation analysis,” Annual Review of Psychology, 58, 593-614.

Meier, Stephan (2007), “Do subsidies increase charitable giving in the long run? Matching donations in a field experiment," Journal of the European Economic Association, 5 (June), 1203-1222.

Miller, Joan G. (1984), "Culture and the development of everyday social explanation," Journal of Personality and Social Psychology, 46 (May), 961-978.

Schultz, P. Wesley (1999) “Changing behavior with normative feedback interventions: A field experiment on curbside recycling,” Basic and Applied Social Psychology, 21 (January), 25-36. 
Shearman, Sachiyo M., and Jina H. Yoo (2007), “’Even a penny will help!’: Legitimization of paltry donation and social proof in soliciting donation to a charitable organization,” Communication Research Reports, 24 (November), 271-282.

Sherif, Muzafer (1936), The psychology of social norms. New York: Harper.

Target Analytics (2009), “Index of National Fundraising Performance,” (accessed 11 September 2013), [available at https://www.blackbaud.com/files/resources/downloads/cam/TargetIndexResultsSummary Q32009.pdf].

Zhang, Ying, Ayelet Fishbach, and Ravi Dhar (2007), “When Thinking Beats Doing: The Role of Optimistic Expectations in Goal-Based Choice,” Journal of Consumer Research, 34 (April), 567-578. 


\section{TABLE 1}

Study 1: Means for Base and Total Amounts Donated, and Total Time Active across Conditions

\begin{tabular}{|c|c|c|c|c|c|c|}
\hline \multirow[b]{2}{*}{ Condition } & \multicolumn{2}{|c|}{ One-Time Donations } & \multicolumn{3}{|c|}{ Recurring Donations } & \multirow[b]{2}{*}{ Average Total (\$) } \\
\hline & $\begin{array}{l}\text { Percent of one- } \\
\text { time donations }\end{array}$ & Base Amount (\$) & $\begin{array}{c}\begin{array}{c}\text { Percent of } \\
\text { upgrades }\end{array} \\
\end{array}$ & Base Amount (\$) & $\begin{array}{c}\text { Time Active } \\
\text { (months) }\end{array}$ & \\
\hline Control & 96.69 & $\begin{array}{c}37.83 \\
(28.88)\end{array}$ & 3.31 & $\begin{array}{c}24.27 \\
(22.13)\end{array}$ & $\begin{array}{r}15.72 \\
(7.89)\end{array}$ & 49.21 \\
\hline Prompt & 97.16 & $\begin{array}{c}37.18 \\
(27.94)\end{array}$ & 2.84 & $\begin{array}{c}19.87 \\
(15.62)\end{array}$ & $\begin{array}{r}12.91 \\
(8.47)\end{array}$ & 43.41 \\
\hline $100 \%$ match & 96.92 & $\begin{array}{c}34.78 \\
(26.45)\end{array}$ & 3.08 & $\begin{array}{r}23.64 \\
(22.30)\end{array}$ & $\begin{array}{l}11.76 \\
(8.81)\end{array}$ & 42.27 \\
\hline Group 25\% & 96.93 & $\begin{array}{c}36.30 \\
(27.88)\end{array}$ & 3.07 & $\begin{array}{r}36.27 \\
(25.88)\end{array}$ & $\begin{array}{l}14.02 \\
(8.56)\end{array}$ & 50.66 \\
\hline Group 50\% & 97.21 & $\begin{array}{c}37.63 \\
(29.10)\end{array}$ & 2.79 & $\begin{array}{r}28.04 \\
(27.79)\end{array}$ & $\begin{array}{r}14.90 \\
(7.70)\end{array}$ & 48.24 \\
\hline Group 75\% & 95.27 & $\begin{array}{c}37.67 \\
(27.93)\end{array}$ & 4.73 & $\begin{array}{r}29.45 \\
(28.68)\end{array}$ & $\begin{array}{l}14.28 \\
(8.03)\end{array}$ & 55.78 \\
\hline Group 100\% & 96.23 & $\begin{array}{c}36.23 \\
(27.27)\end{array}$ & 3.77 & $\begin{array}{c}24.10 \\
(20.74)\end{array}$ & $\begin{array}{l}13.57 \\
(8.47)\end{array}$ & 47.19 \\
\hline
\end{tabular}

* Average Total (\$) was calculated by adding the product of the Base Amount for One-Time Donations and the percentage of onetime donations to the product of the Base Amount for Recurring Donations, the percentage of recurring donations, and Time Active. 
TABLE 2

Study 2: Means for Social Proof, Plausibility, Progress and Perceived Impact across Conditions

\begin{tabular}{lcccc} 
Condition & Social Proof & Plausibility & Progress & $\begin{array}{c}\text { Perceived } \\
\text { Impact }\end{array}$ \\
\hline \hline Control & $30.75 \%(20.00 \%)^{\mathrm{a}}$ & $4.20(1.45)^{\mathrm{a}}$ & $3.24(1.41)^{\mathrm{a}}$ & $2.89(1.27)^{\mathrm{a}}$ \\
Group 25\% & $26.65 \%(18.19 \%)^{\mathrm{a}}$ & $4.02(1.73)^{\mathrm{a}}$ & $2.89(1.49)^{\mathrm{a}}$ & $2.71(1.41)^{\mathrm{a}}$ \\
Group 50\% & $40.87 \%(21.59 \%)^{\mathrm{b}}$ & $3.75(1.53)^{\mathrm{a}}$ & $2.87(1.36)^{\mathrm{a}}$ & $2.89(1.40)^{\mathrm{a}}$ \\
Group 75\% & $48.80 \%(23.17 \%)^{\mathrm{c}}$ & $4.05(1.67)^{\mathrm{a}}$ & $3.75(1.43)^{\mathrm{b}}$ & $3.67(1.56)^{\mathrm{b}}$ \\
Group 100\% & $47.44 \%(27.45 \%)^{\mathrm{c}}$ & $2.62(1.71)^{\mathrm{b}}$ & $3.33(1.61)^{\mathrm{a}}$ & $3.38(1.63)^{\mathrm{b}}$
\end{tabular}

a,b, c Within each column, values with the same superscripts are not significantly different from each other. 


\section{FIGURE 1}

Study 1: Recurring Donation Conversion Percentages across Conditions

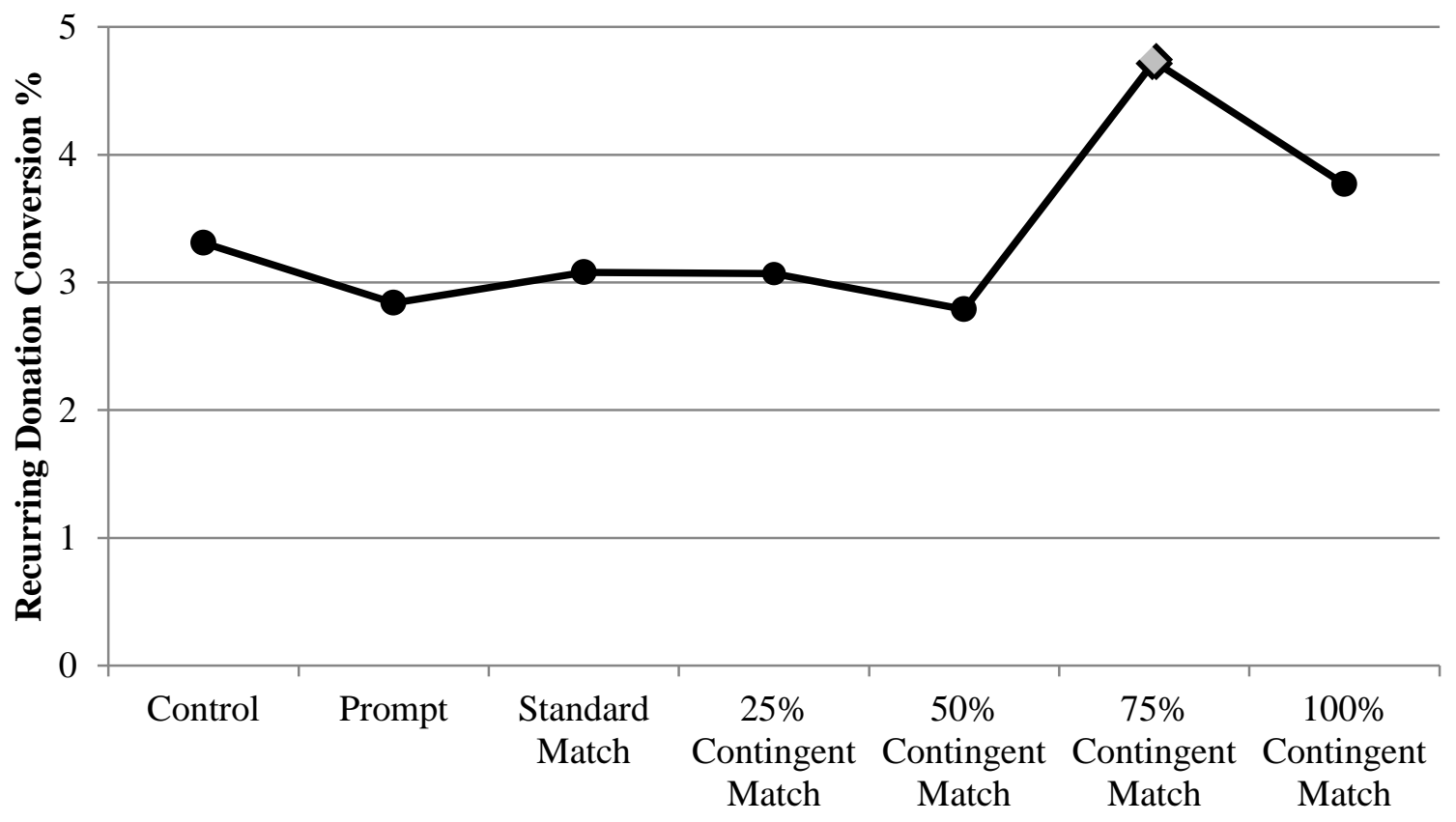

Note. Values that are not significantly different are shown with the same data marker; only the conversion rate for the $75 \%$ contingent match condition differed from the others. 


\section{FIGURE 2}

Study 2: Recurring Donation Conversion Percentages across Conditions

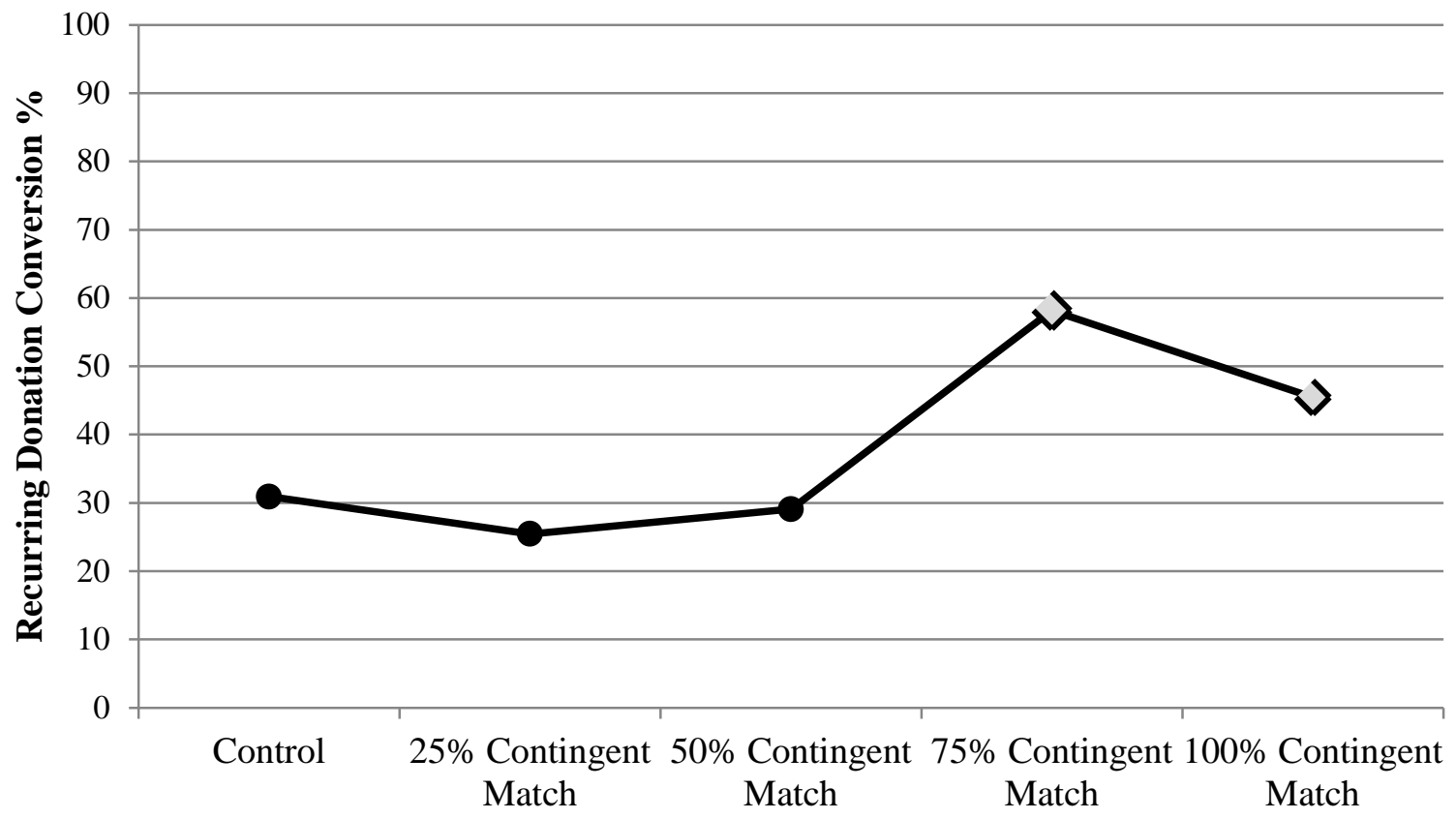

Note. Values that are not significantly different are shown with the same data marker; the conversion rate for the $75 \%$ contingent match and 100\% contingent match condition differed from the others, but not from each other. 
FIGURE 3

Study 2: Results of the Mediation Analyses

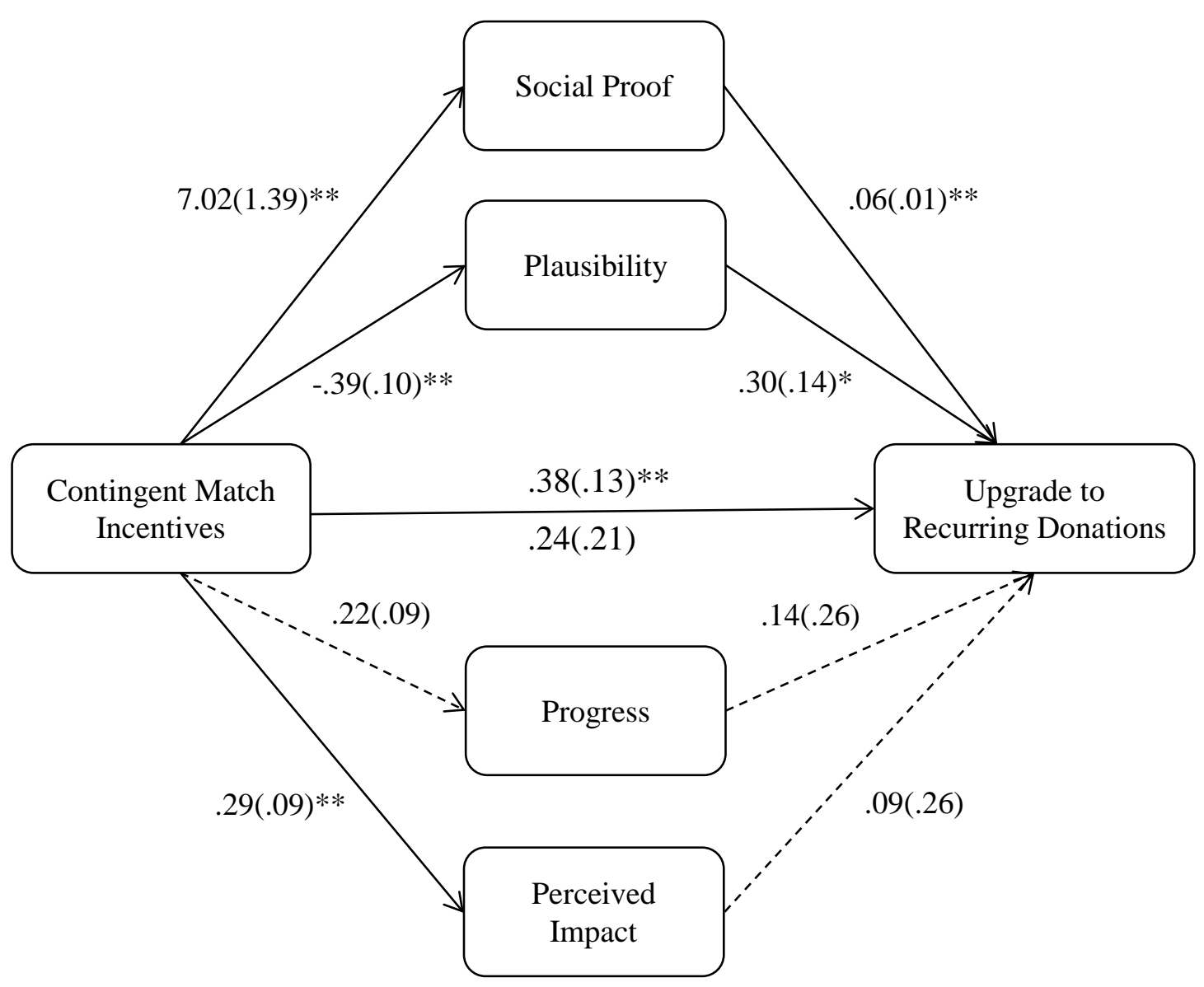

Unstandardized regression coefficients are shown, and standard errors are presented in parentheses. The coefficient above the path from condition to conversion to recurring donations represents the total effect with no mediators in the model; the coefficient below the path represents the direct effect when the mediators were included in the model. Coefficients significantly different from 0 are indicated by asterisks $\left({ }^{*} p<.05\right.$, $\left.{ }^{*} p<.001\right)$, and their associated paths are shown by solid lines; dashed lines indicate nonsignificant paths. 


\section{APPENDIX A: Study 1}

\section{Panel 1: Screenshot of a sample project page}

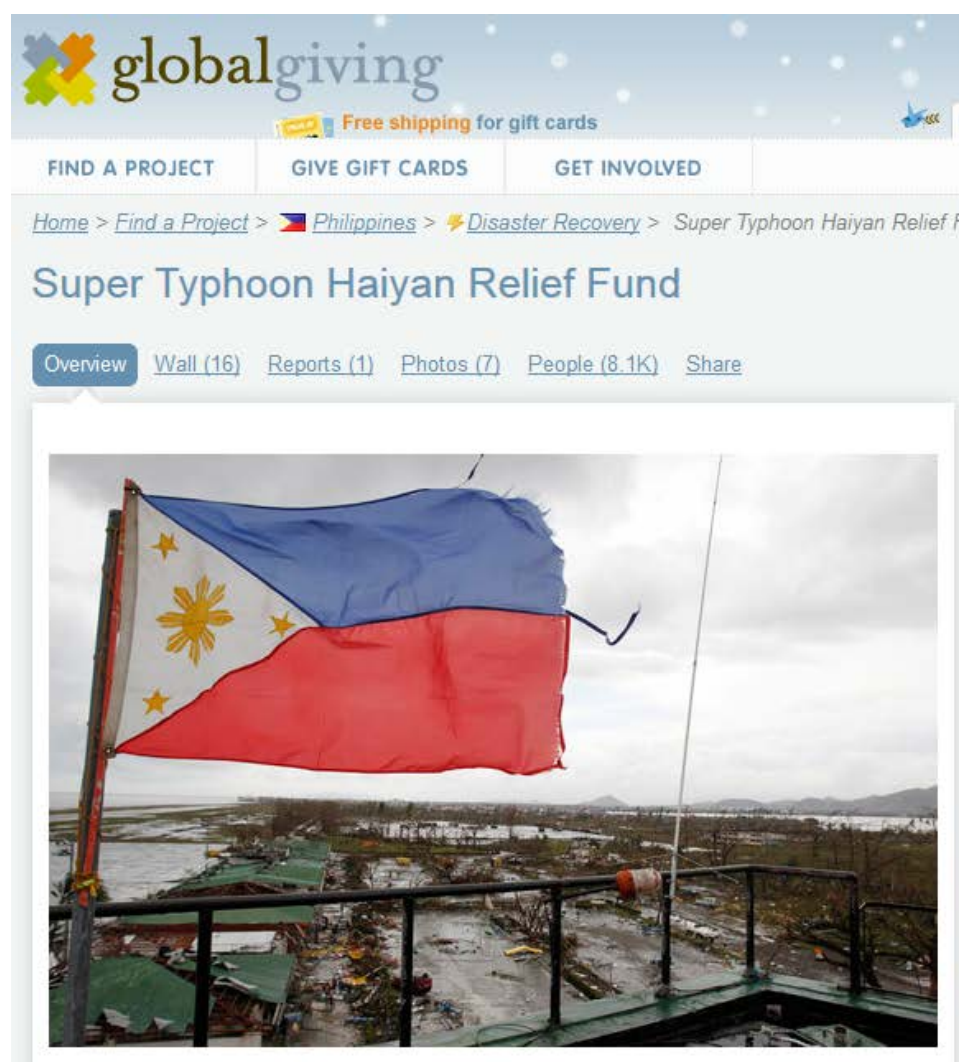

\begin{tabular}{|c|c|c|c|}
\hline$\$ 850,573$ & $\$ 149,427$ & 9,092 & -1 \\
\hline Raised & Remaining & Donations & Report \\
\hline \multicolumn{4}{|c|}{ donate } \\
\hline
\end{tabular}
- \$25 emergency disaster and long-term relief for victims

( $\$ \mathbf{5 0}$ emergency disaster and long-term relief for victims

\$75 emergency disaster and long-term relief for victims

(- $\$ 100$ emergency disaster and long-term relief for victims 
Panel 2: Screenshot of the check-out page for the control condition

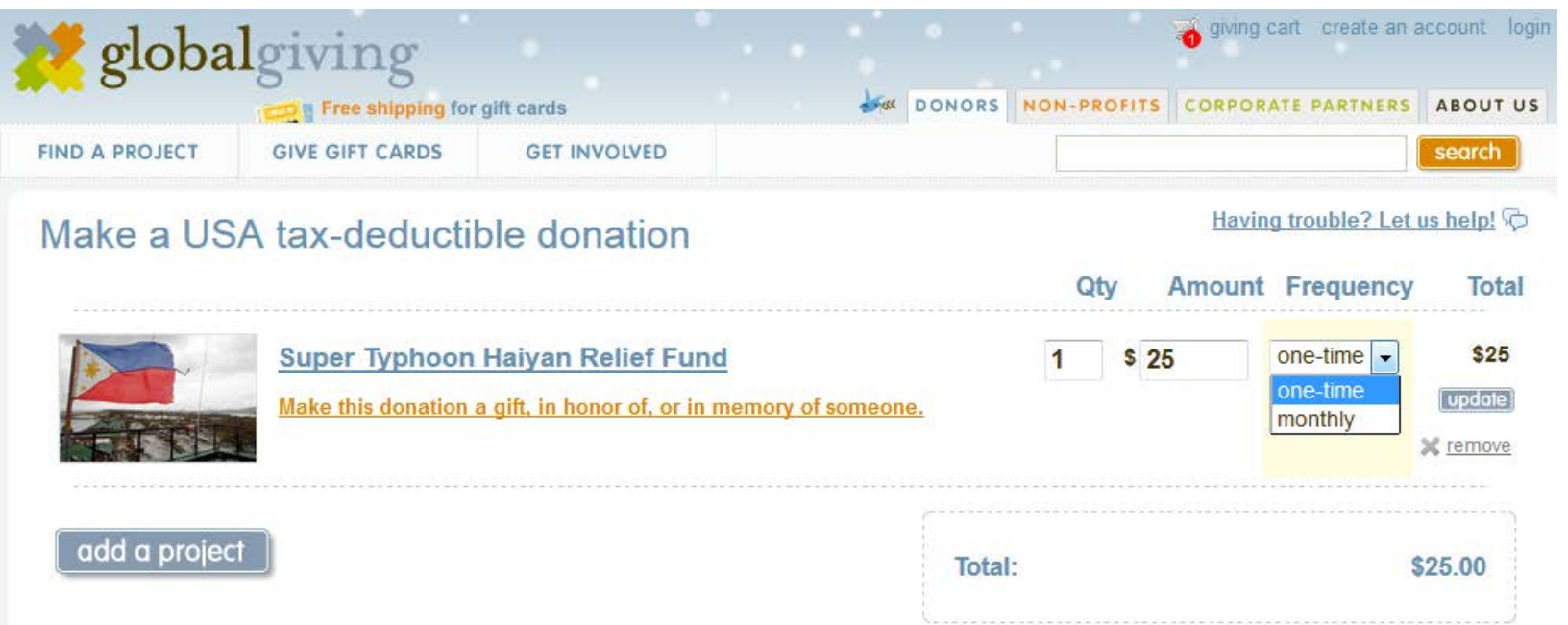

Panel 3: Screenshot of the check-out page for the $75 \%$ contingent match condition

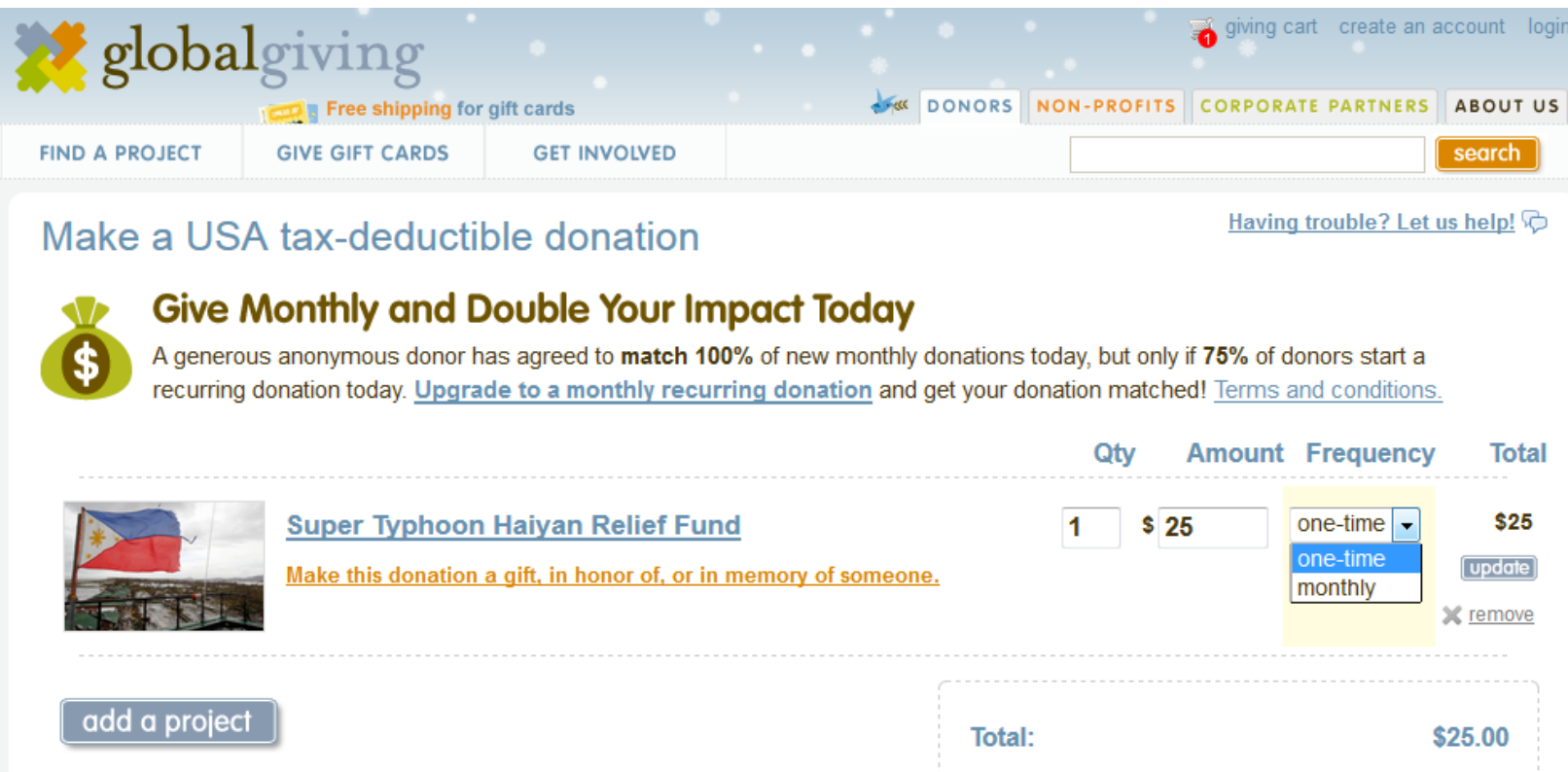


APPENDIX B: Study 2

The single page of information viewed by participants (75\% contingent match condition)

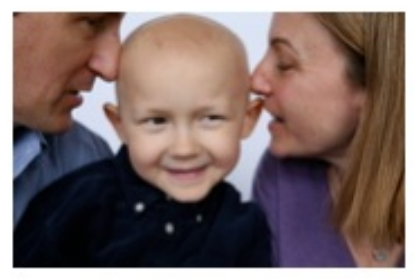

\section{Bring Joy to Seriously III Children}

Countries: United States

Themes: Health, Children

When seriously ill kids \& their families need more than medicine, the Children's

Cancer Association is there with compassion and innovation creating moments of respite and hope, in the hospital and at home. CCA brings soothing music in a time of crisis, friendship in a time of loneliness, resources in a time of turmoil and vital support in the midst of life-threatening illness.

Though you may choose to donate any amount you would like, here is an overview of what different amounts of help would get these kids:

$\$ 25$ - fills an iPod with a hospitalized child's favorite songs

$\$ 50$ - will help fill a Chemo Pal activity bag with toys

$\$ 100$ - fills the pantry for a weekend getaway at the Caring Cabin

\section{Now also imagine that the following message is displayed:}

We are excited to announce that an anonymous donor has agreed to provide matching funds for people who donate today.

We will match your donation if you upgrade to a recurring donation, but whether we match your donation or not depends on how many people create monthly recurring donations on Global Giving. If $75 \%$ of people seeing this offer agree to upgrade to a monthly recurring donation today, we will match $100 \%$ of your donation. For example, if you give $\$ 10$ per month, we will donate an additional $\$ 10$ today, but only if $75 \%$ of people who see this message upgrade to recurring donation today.

Make a monthly recurring donation - the more people who donate, the higher the matching goes! 